\title{
Factors of accepting pain management decision support systems by nurse anesthetists
}

\author{
Ju-Ling Hsiao", Wen-Chu Wu ${ }^{2}$ and Rai-Fu Chen ${ }^{3^{*}}$
}

\begin{abstract}
Background: Pain management is a critical but complex issue for the relief of acute pain, particularly for postoperative pain and severe pain in cancer patients. It also plays important roles in promoting quality of care. The introduction of pain management decision support systems (PM-DSS) is considered a potential solution for addressing the complex problems encountered in pain management. This study aims to investigate factors affecting acceptance of PM-DSS from a nurse anesthetist perspective.

Methods: A questionnaire survey was conducted to collect data from nurse anesthetists in a case hospital. A total of 113 questionnaires were distributed, and 101 complete copies were returned, indicating a valid response rate of 89.3\%. Collected data were analyzed by structure equation modeling using the partial least square tool.

Results: The results show that perceived information quality $(\gamma=.451, p<.001)$, computer self-efficacy $(\gamma=.315, p<.01)$, and organizational structure $(\gamma=.210, p<.05)$, both significantly impact nurse anesthetists' perceived usefulness of PM-DSS. Information quality $(\gamma=.267, p<.05)$ significantly impacts nurse anesthetists' perceptions of PM-DSS ease of use. Furthermore, both perceived ease of use $\left(\beta=.436, p<.001, R^{2}=.487\right)$ and perceived usefulness $(\beta=.443, p<.001$, $\left.R^{2}=.646\right)$ significantly affected nurse anesthetists' PM-DSS acceptance $\left(R^{2}=.640\right)$. Thus, the critical role of information quality in the development of clinical decision support system is demonstrated.
\end{abstract}

Conclusions: The findings of this study enable hospital managers to understand the important considerations for nurse anesthetists in accepting PM-DSS, particularly for the issues related to the improvement of information quality, perceived usefulness and perceived ease of use of the system. In addition, the results also provide useful suggestions for designers and implementers of PM-DSS in improving system development.

Keywords: Pain Management, Decision support systems, Technology acceptance model, Anesthesiologist, Nurse-Anesthetist

\section{Background}

Clinical decision support systems (CDSS) for nursing staffs Nursing staff are the major group of healthcare professionals who perform crucial functions in delivering nursing care to inpatients. In addition, they work with patients and other caregivers and in collaboration with medical staff as members of multidisciplinary teams. Therefore, inappropriate or incompetent nursing actions endanger patient safety [1,2]. Traditionally, the duties of nursing personnel include (1) nursing assessments of health problems, (2) nursing measures for preventative

\footnotetext{
* Correspondence: rafuchen@gmail.com

${ }^{3}$ Department of Information Management, Chia-Nan University of Pharmacy and Science, No.60, Sec. 1, Erren Rd., Rende Dist, Tainan City 71710, Taiwan, Republic of China

Full list of author information is available at the end of the article
}

healthcare, (3) nursing guidance and counseling, and (4) auxiliary medical care [3]. With the rapid changes in the delivery of healthcare, prior studies have indicated that nurses are undertaking extended roles, such as nurse practitioners (NP) and nurse anesthetists [3]. The introduction of clinical decision support systems (CDSS) is a possible method of supporting nurses within their extended roles and enhancing patient safety and quality of care [4-9]. Kawamoto et al. [10] showed that features of automatic provision for decision support as part of clinicians' workflow, provision recommendations rather than only assessments, provision decision support at the time and location of decision making, and computerbased decision support are closely correlated with decision support systems' abilities to significantly enhance 
patient care. Although there is scant research focusing on nurses' use of CDSS compared with research focusing on doctors' use of CDSS, some studies have revealed examples of CDSS in supporting nurses' decision making in the management of angina [11] and diabetes [12], cancer pain [13], and triage for patients in first contact care $[14,15]$.

\section{A need for pain management}

Pain is regarded as the fifth vital sign in health assessment of patients' statuses. Nurses, especially those with expertise in pain management, are valuable resources as health care organizations alter their pain assessment and management processes to meet pain standards [16]. Relieving pain during medical treatment is a common but critical healthcare issue encountered by healthcare institutions. However, meeting patient requirements for pain management is difficult because of individual differences regarding analgesic needs. To overcome the problem of traditional analgesia, the concept of pain management (pain control) or humanistic analgesia has been introduced to provide analgesia for postoperative pain in patients according to their needs, and to enable patients to participate in the analgesic process [9,17].

Prior study indicated that individualized pain management should take into account the onset, type, site, duration, intensity, and temporal patterns of the pain, concurrent medical conditions [18]. In addition, the study argued that the subjective perception of the intensity of pain that is not proportional to the type or to the extension of the tissue damage but depends on the interaction of physical, cultural, and emotional factors. Sun et al. [19] summarized the barriers to cancer pain assessment and management into three categories: patient, professional and system barriers. They found that lack of knowledge of the principles of pain relief, side effect management, or understanding of key concepts such as addiction, tolerance, dosing, and treatment of neuropathic pain are professional barriers affecting pain assessment and management. Thus, pain management is a critical and complex issue for anesthesiology.

The success of pain management depends on nurse anesthetists constantly monitoring patient statuses and making appropriate clinical assessments and analgesics based on patients' statuses. Consequently, it is critical to provide a pain management decision support system (PM-DSS) for nurse anesthetists to assist in pain assessment, diagnosis, and intervention [12]. Randell et al. [20] found that nurses' experience with the decision and the technology affected how they used a decision support system. They suggested that a nurses' experience and their ability to adapt the technology to 'fit' their clinical practice is critical for the CDSS use.

\section{Pain management decision support systems (PM-DSS)}

The pain management decision support system (PMDSS), a CDSS and subsystem of healthcare or hospital information systems (HIS), provides decision support capabilities to healthcare professionals during patient pain management. Quinzio et al. [21] found that introducing an anesthesia information management system can enhance the quality of nurse anesthetists' work. A PM-DSS can assist nurse anesthetists in collecting, storing, processing, acquiring, displaying, and transmitting data related to pain management. A prior study indicated that decision support systems for cancer pain management should include (1) a knowledge base generation module, (2) a decision-making module, and (3) a self-adaptation module [22]. Therefore, the PM-DSS developed in this study provides the following functions: (1) pain management services and information management during analgesic care (i.e., preoperative preparation, postoperative practice, and anesthetic practice); (2) provision of standardized patient care information during analgesic care; and (3) analysis of a pain management database to provide reference formulae for analgesia dosages suitable for patients' physical conditions.

The PM-DSS records relevant aspects of pain management, ranging from patient admission to clinical care or hospice care units. Patient demographics and laboratory data are imported from the HIS and are supplemented with data that has been imported automatically from previous procedures and pain assessments. Data from respirators and vital-sign monitors are automatically gathered at defined intervals where compatible device interfaces are available [17].

\section{A need for understanding the acceptance of clinical decision support systems}

Prior studies have found that users' acceptance of information technology (IT) is crucial in determining whether IT promotion is successful [23,24]. Therefore, acceptance by healthcare professionals is essential for the successful adoption and implementation of healthcare-related systems [2,22-26]. Because the development of PM-DSS and CDSS in Taiwan remains in an early stage, an in-depth study must be conducted promptly to examine the factors that affect the successful development of PM-DSS in Taiwan. Randell and Dowding [27] found that clinician engagement is the critical element in the successful introduction of CDSS. Nurse anesthetists are crucial providers and operators in the processes of pain control and management, and their acceptance of PM-DSS is essential to success. When the PM-DSS is implemented, the opinions of nurse anesthetists must be the focus, concerning the extent to which the system helps them to integrate patient data rapidly and monitor patients' vital signs in a timely 
manner and enables patients to experience a safe and mild pain-control process.

This study investigated factors affecting PM-DSS acceptance from the perspective of nurse anesthetists using PM-DSS in a case hospital that implemented the system to support pain management decision processes. The research question of this study was "what critical factors affect nurse anesthetists' PM-DSS acceptance?" The study results can help hospital managers understand the factors that affect PM-DSS use, thereby providing a reference when systems are introduced or promoted in the future.

The remainder of this paper is organized as follows. Methods describes the theoretical foundations, theoretical framework, instruments and participants, and methods for data analysis. Results shows the results. Discussion details an in-depth examination of the findings of this study. Finally, we address implications and offer a conclusion in Conclusions.

\section{Methods}

\section{Theoretical foundations}

The key to successful information systems lies in evaluating system acceptance from the users' perspective [28]. The Technology Acceptance Model (TAM), originally proposed by Davis [29], is one of the most widely used theoretical models for predicting and explaining whether users will accept new IT or other systems [30]. Although the TAM has been applied to investigate factors affecting healthcare professionals' acceptance of healthcare information technology (HIT) applications [31-38], inconsistent results have been found because of inherent differences between various user groups and application systems [24,33]. For example, research has shown that perceived usefulness and perceived ease of use may play a significant role in CDSS use among clinicians, but the influence of perceived ease of use is not significantly supported for other types of healthcare technologies [32]. Prior studies have found that TAM constructs are valid for healthcare professionals $[2,25,26,38,39]$, but the perceived ease of use is not consistently related to attitudes $[28,40]$.

Wu et al. [40] argued that TAM focuses more on technological aspect and its strengths are its parsimony and high explanatory power. They also indicated that TAM lacks consideration of the effects of human and organizational factors. Yarbrough and Smith [28] argued that one limitation of the TAM is its inability to consider the influence of external variables and barriers to technology acceptance. They suggested customizing the inclusion of variables to enhance the model's accuracy. They further concluded that the major barriers to clinicians' acceptance of systems can be classified into three major categories: human (personal) characteristics, organizational characteristics, and IS characteristics. In addition, Yusof et al. [38] proposed a human, organization, and technology-fit (HOT-fit) framework for evaluating the success of health information systems by emphasizing a good fit among human, organizational, and technical elements of the system. In their study, human factors included system use and user satisfaction; organizational factors included organization structure and environment; and technology factors included system quality, information quality, and service quality. These are considered the potential factors affecting PM-DSS acceptance.

Studies have been conducted to evaluate HIT from partial dimensions of the HOT-fit framework [27,41]. Randell and Dowding [27] emphasized organizational influences on nurses' uses of CDSSs. They found that the key factors for the introduction of a CDSS are instigation from individual clinicians, initiatives at policy level, clinician engagement, the need for adequate resources, the characteristics of the system itself, and adequate training. Fitterer et al. [41] proposed a taxonomy for a multi-perspective assessment of HIT values in accordance with human and organizational considerations. They found system use to be related to people who use it, their level of use, their training, and their attitudes toward the system. Organizational factors consist of organizational structure, leadership, top management support, and medical staff sponsorship.

\section{Theoretical framework}

To provide an in-depth investigation on factors affecting PM-DSS acceptance from the perspective of nurse anesthetists, we propose an extended TAM, as shown in Figure 1, derived from Davis' original TAM framework [29] and the HOT-fit framework proposed by Yusof et al. [42]. The model emphasizes the influence of external variables and barriers to technology by incorporating the HOT-fit framework as the external factors of the TAM, as suggested by Yarbrough and Smith [28] and Yusof et al. [42]. These barrier factors could indirectly affect user attitudes and behavior intention toward IT use. Thus, the extended TAM consists of nine constructs: system quality, information quality, innovativeness, computer self-efficacy, organizational environment, organizational structure, perceived usefulness, perceived ease of use, and PM-DSS acceptance.

The IS barrier includes considerations of (1) system quality, that is, system response, system reliability, and security, and (2) information quality, meaning integrity, accuracy, format, completeness, and timeliness of information [43]. The development of a PM-DSS is a complex but important task for decision support on pain management in medical institutes. Therefore, measuring and evaluating the value and effectiveness of a PM-DSS is critical. Lu et al. [39] found that system quality and 


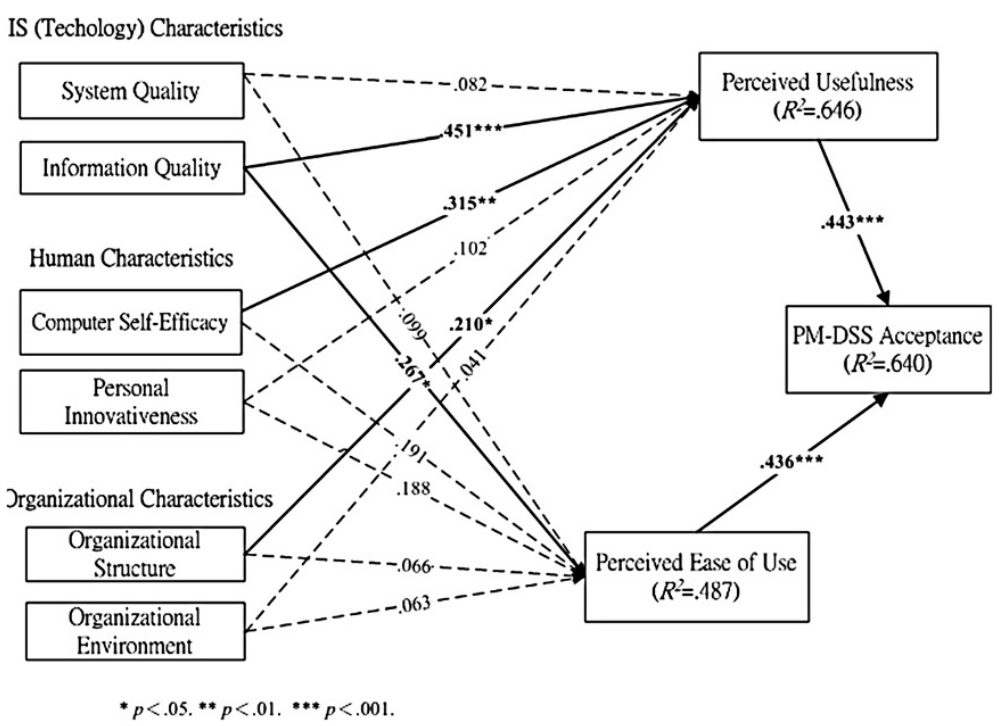

Figure 1 Result of model validity regarding factors affecting nurse-anesthetists PM-DSS acceptance.

information quality are key factors influencing the perceived usefulness and perceived ease of use of an HIS. In addition, a previous study found that system quality and information quality are major factors affecting willingness and satisfaction in system use [44].

The human (personal) barrier includes (1) user selfefficacy (i.e., the ability of people to believe that they must apply IT systems to complete specific tasks) [45,46], and (2) personal innovativeness, representing the degree to which people are willing to take risks by test an innovation $[47,48]$. Prior research found that users are happier using IT when they have confidence in their ability to use computers [49]. Ong and Lai [50] found that users' computer self-efficacy is a significant determinant of perceived usefulness and perceived ease of use in the context of e-learning. This finding implied that users with high computer self-efficacy are likely to have more positive usefulness and ease of use beliefs. In addition, past studies found that a higher level of personal innovativeness can lead to greater intention to use new technology [51], and a direct and positive correlation exists between personal innovativeness and personal perception of new technology benefits [52]. Accordingly, whereas healthcare professionals usually work in an independent decision-making manner for patient treatment and the early use of a PM-DSS is considered in a voluntary mode, personal innovativeness is argued as an important determinant of attitude toward using a PM-DSS.

The organizational barrier involves the following: (1) Organizational structure is a tool and instrument used by enterprises to achieve their objectives and to dominate and coordinate decision-making activities [53], and it may include type and size (number of beds), culture, politics, hierarchy, autonomy, planning and control systems, strategy, management and communications, leadership, top management support, and medical staff sponsorship [42], and (2) organizational environment, in the context of the environment in which the organization exists, includes external competition, influence of government policies, characteristics of target audience, and source of funds required for unit operations $[42,54,55]$. Kaplan [56] argued that the nature of a healthcare institution can be examined from its structure and environment. Yusof et al. [42] argued that organizational structure has an impact on system use, and they considered that organizational structure and organizational environment have influences on net benefits obtained from the use of an IS. Prior studies have found that external competition, influence of government policies, characteristics of target audience, and source of funds required for introducing new IS $[42,54,55]$ are key factors for successful IT implementation. For example, patient safety initiatives and the promotion of electronic medical records (EMR) have led to an increased demand for PM-DSS development in hospitals in recent years $[6,42]$.

Perceived usefulness represents users' subjective beliefs in the benefits of using HIT to achieve job goals within medical practice [57]. When nurse anesthetists perceive a higher degree of system usefulness, they have more of a positive attitude and are willing to accept the PM-DSS. Perceived ease of use refers to the degree to which users believe that using HIT frees from effort [28]. Once users perceive that it is easier to learn how to use a system, they adopt a more positive attitude in accepting the system. According to the TAM, perceived usefulness and perceived ease of use both affect users' attitude toward using IT, which consequently affects the actual behaviors 
of users [29]. Perceived ease of use also strengthens the users' perception of the usefulness of IT; for example, if IT saves them time so that they can spend it on other tasks, this enhances their attitude toward IT use [28]. Huryk [58] found that the perception of enhanced patient care or safety and a system that was easy to use or integrated well into the nurses' workflow were factors that lead toward a positive attitude. In addition, Aldosari [25] found that perceived ease of use and perceived usefulness are critical factors for user acceptance of picture archiving and communication systems (PACS). Satisfaction is often considered an important variable of IS success in the post-implementation stage [44]. In this study, we adopted satisfaction to measure system acceptance $[59,60]$. As discussed, we propose the following eight hypotheses:

$\mathrm{H}_{1}$ : IS factors have a significant impact on nurse anesthetists' perceived PM-DSS usefulness.

$\mathrm{H}_{1 \mathrm{a}}$ : PM-DSS system quality affects nurse anesthetists' perceived PM-DSS usefulness.

$\mathrm{H}_{1 \mathrm{~b}}$ : PM-DSS information quality affects nurse anesthetists' perceived PM-DSS usefulness $\mathrm{H}_{2}$ : IS factors have a significant impact on nurse anesthetists' perceived PM-DSS ease of use. $\mathrm{H}_{2 \mathrm{a}}$ : PM-DSS system quality affects nurse anesthetists' perceived PM-DSS ease of use.

$\mathrm{H}_{2 \mathrm{~b}}$ : PM-DSS information quality affects nurse anesthetists' perceived PM-DSS ease of use. $\mathrm{H}_{3}$ : Human factors significantly affect nurse anesthetists' perceived PM-DSS usefulness. $\mathrm{H}_{3 \mathrm{a}}$ : Computer self-efficacy affects nurse anesthetists' perceived PM-DSS usefulness.

$\mathrm{H}_{3 \mathrm{~b}}$ : Personal innovativeness affects nurse anesthetists' perceived PM-DSS usefulness.

$\mathrm{H}_{4}$ : Human factors significantly affect nurse anesthetists' perceived PM-DSS ease of use.

$\mathrm{H}_{4 \mathrm{a}}$ : Computer self-efficacy affects nurse anesthetists' perceived PM-DSS ease of use.

$\mathrm{H}_{4 \mathrm{~b}}$ : Personal innovativeness affects nurse anesthetists' perceived PM-DSS ease of use.

$\mathrm{H}_{5}$ : Organizational factors significantly affect nurse anesthetists' perceived PM-DSS usefulness.

$\mathrm{H}_{5 \mathrm{a}}$ : Organizational structure affects nurse anesthetists' perceived PM-DSS usefulness.

$\mathrm{H}_{5 \mathrm{~b}}$ : The organizational environment affects nurse anesthetists' perceived PM-DSS usefulness.

$\mathrm{H}_{6}$ : Organizational factors significantly affect nurse anesthetists' perceived PM-DSS ease of use.

$\mathrm{H}_{6 \mathrm{a}}$ : Organizational structure affects nurse anesthetists' perceived PM-DSS ease of use.

$\mathrm{H}_{6 \mathrm{~b}}$ : The organizational environment affects nurse anesthetists' perceived PM-DSS ease of use.

$\mathrm{H}_{7}$ : Nurse anesthetists' perceived PM-DSS ease of use affects system acceptance.
$\mathrm{H}_{8}$ : Nurse anesthetists' perceived PM-DSS usefulness of PMDSS affects system acceptance.

\section{Instrument and subjects}

The initial research framework and questionnaires were developed through a literature review, and were revised by three experts in the anesthetic and medical-information field. These experts evaluated the content validity of the questionnaire, in which the measurement of expert validity is based on a content validity index (CVI) of 0.8 [61], and the overall CVI is 0.97 , indicating excellent expert validity.

We collected empirical data from nurse anesthetists with more than one year of experience in interventional pain management. The case hospital was a private facility with 2100 beds, which had existed for over 40 years. The hospital is an early adopter in introducing innovative HIT in Taiwan, such as HIS, picture archiving and communication systems (PACS), and EMRs. The hospital is the earliest adopter in implementing mobile healthcare technology, namely mobile nursing information systems, to provide nursing staff with a more efficient manner in obtaining required information from HISs in a timely manner by using a portable information device and wireless technology. In 2010, the hospital established a PM-DSS to provide enhanced clinical diagnostic services and improve patient satisfaction. At present, the hospital has incorporated mobile healthcare technology into the PM-DSS to improve patient safety and quality of care. Nurse anesthetists were asked to use the PM-DSS in the processes of pain management. For these reasons, the hospital was selected as the case hospital in this study.

This study employed a survey methodology using a 39-item structured questionnaire, which was composed of two major parts: (1) recording the respondents' demographic data, and (2) investigating factors affecting the acceptance of a PM-DSS. The questionnaire items were measured using a 5-point Likert scale, scored from 1 (strongly disagree) to 5 (strongly agree).

The IS construct included system quality and information quality, measured using eight items adapted from Otieno, Toyama, Asonuma, Kanai-Pak, and Naitoh [62] and Wixom and Todd [60]. The personal construct included user self-efficacy and innovativeness, measured using seven questions adapted from Vijayasarathy [49] and Agarwal and Karahanna [51]. The organizational construct addressed organizational structure and organizational environment, measured by 11 items adapted from Yusof et al. [42] and Sciulli [53]. Perceived usefulness was measured by eight items adapted from Wakefield et al. [57], and perceived ease of use was measured by three items adapted from Wixom and Todd [60]. PM-DSS acceptance was measured using two items adapted from Wixom and Todd [60]. 
Detailed descriptions of the questionnaire used in this study are provided in Table 1.

\section{Ethical considerations}

To address potential ethical concerns, our study protocol and informed consent forms were reviewed and approved by the institutional review board (IRB) before the surveys were distributed and collected. After receiving approval from the IRB of the target hospital, research was conducted from mid-December to mid-January, 2011. Study participation was voluntary. Responses were anonymous and untraceable to individual nurses.

\section{Data analysis}

The reliability and validity of the measurement model were assessed by confirmatory factor analysis (CFA) [63-65] by using the SmartPLS 2.0 software with the bootstrap resampling method (1000 resamples) to estimate the parameters of the research model. We used structural equation modeling (SEM) by employing the partial least squares (PLS) tool for data analysis [66] to examine the causal model.

\section{Results}

\section{Demographic data}

The survey was distributed to 113 nurse anesthetists of the case hospital, and 101 completed questionnaires were returned, indicating a valid response rate of $89.3 \%$. This high response rate can be attributed to the top management support and voluntary participation of the respondents of the case hospital. All respondents were women. Most (91.0\%) had a graduate diploma, and $83.1 \%$ had over 5 years of clinical practice experience. Most respondents (76.2\%) were aged between 31 and 40 years. Almost all respondents (97\%) have over 5 years of HIS experiences, and all respondents had more than 3 months of PM-DSS experience. Thus, the sample demographics showed that most respondents were experienced users in HISs and had rich experiences in clinical practice. The demographic data of the partcipants were shown in Table 2.

\section{Measurement model}

Assessing the measurement model of this study involved testing the reliability, convergent validity, and discriminate validity [63]. The reliability and validity results of the research model are shown in Table 3. Constructs included reflective indicators and principal component analysis (PCA), provided by PLS, which ensured the unidimensionality of the constructs. PCA was used to determine that all indicators were significantly associated with only one latent variable, indicating the establishment of unidimensionality [67]. Composite reliability (CR) and average variance extraction (AVE) were used to evaluate reliability and convergent validity. The values of CR (>.810) and AVE $(>.50)$ of all the constructs exceeded the recommended cutoff values of .7 and .5 , representing good reliability and convergent validity. One criterion for adequate discriminant validity is that the square root of the AVE for each construct exceeds the correlation between the construct and other constructs in the research model [63]. All AVEs in this study were greater than the correlation coefficients, indicating good discriminant validity. As shown, this study had adequate reliability, convergent validity, and discriminant validity.

\section{Hypothesis testing}

SEM was used to test the structural model and to enable examining the effects among the nine latent variables. As shown in Figure 1 and Table 4, six hypotheses were supported significantly in this study. Information quality $(\gamma=.451, p<.001)$ in IS characteristics, computer selfefficacy $(\gamma=.315, p<.01)$ in human characteristics, and organizational structure $(\gamma=.210, p<.05)$ in organizational characteristics had a significant impact on nurse anesthetists' perceptions of PM-DSS usefulness, supporting $\mathrm{H}_{1 \mathrm{~b}}, \mathrm{H}_{3 \mathrm{a}}$, and $\mathrm{H}_{5 \mathrm{a}}$. Information quality $(\gamma=.267, p<.05)$ in IS factors significantly affects nurse anesthetists' perceptions of PM-DSS ease of use, supporting $\mathrm{H}_{2 \mathrm{~b}}$. Finally, perceived ease of use $(\beta=.436, p<.001$, $\left.\mathrm{R}^{2}=.487\right)$ and perceived usefulness $(\beta=.443, p<.001$, $\left.\mathrm{R}^{2}=.646\right)$ significantly affected PM-DSS acceptance $\left(\mathrm{R}^{2}=.640\right)$, supporting $\mathrm{H}_{7}$ and $\mathrm{H}_{8}$. This implied that perceived ease of use and perceived usefulness account for $64 \%$ of the total explained variance in nurse anesthetists' acceptance of PM-DSS. However, inconsistent with our hypotheses, the data show that system quality, personal innovativeness, and organizational environment have no significant impact on perceived usefulness $\left(\mathrm{H}_{1 \mathrm{a}}, \mathrm{H}_{3 \mathrm{~b}}\right.$, and $\left.\mathrm{H}_{5 \mathrm{~b}}\right)$ and perceived ease of use $\left(\mathrm{H}_{2 \mathrm{a}}, \mathrm{H}_{4 \mathrm{~b}}\right.$, and $\left.\mathrm{H}_{6 \mathrm{~b}}\right)$.

\section{Discussion}

This study proposed an extended TAM by incorporating Davis' original TAM framework [29] and the HOT-fit framework of Yusof et al. [42] to investigate the critical factors affecting PM-DSS acceptance from nurse anesthetists' perspectives. The major findings of this study included that (1) information quality significantly affects the perceived ease of use of PM-DSS; (2) information quality, organizational structure, and computer self-efficacy significantly influence the perceived usefulness of PM-DSS; and (3) perceived ease of use and perceived usefulness influence PM-DSS acceptance by nurse anesthetists. The data showed that perceived usefulness has a substantial influence that is slightly greater than that of perceived ease of use on PM-DSS acceptance by nurse anesthetists. 
Table 1 Questionnaire

\begin{tabular}{|c|c|}
\hline Item no. & Item description \\
\hline 1.SQ1 & The PM-DSS is stable. \\
\hline 2.SQ2 & The response time of PM-DSS is speedy. \\
\hline $3.5 Q 3$ & The data accessibility of PM-DSS is good. \\
\hline 4.SQ4 & The effectiveness of PM-DSS security to prevent unauthorized access to patient data. \\
\hline $5.1 \mathrm{Q} 1$ & The PM-DSS can integrate data from different sources. \\
\hline $6.1 Q 2$ & The information of PM-DSS is accurate. \\
\hline $7.1 \mathrm{Q} 3$ & The content and its display format of PM-DSS can fulfill user needs. \\
\hline $8.1 Q 4$ & The information of PM-DSS is up-to-date. \\
\hline 9.IN1 & If I heard that a new technology was available, I would be interested enough to test. \\
\hline 10.IN2 & I prefer to use the most advanced technology available. \\
\hline 11.IN3 & In general, I hesitate to try new information system. \\
\hline 12.CS1 & I could complete the job using PM-DSS if I had never used a system like it before. \\
\hline 13.CS2 & I could complete the job using PM-DSS if I had used similar system before PAIN MANAGEMENT DSS one to do the same job. \\
\hline 14.CS3 & I have the ability to operate PM-DSS. \\
\hline 15.CS4 & I prefer to use a PM-DSS for patient visit. \\
\hline 16.051 & The employee should follow the clinical standard of procedures to complete clinical practice. \\
\hline 17.052 & The employee could share his opinions with the supervisors and participate the decision processes in the pain management. \\
\hline 18.053 & The duties and rights for the pain management were clarified in the work field and all were documented. \\
\hline 19.054 & Greater degree of coordination achieved by grouping all those working on the pain management. \\
\hline 20.055 & The clinical consultation problems would be resolved by many different ways. \\
\hline 21.0S6 & There were champions for development of the PM-DSS. \\
\hline 22.OE1 & The adoption of information technology in the hospital, which you serve, will be affected by medical policies. \\
\hline 23.OE2 & The degree of competition among local hospitals is high. \\
\hline 24.OE3 & The degree of computerization in our hospitals is high. \\
\hline 25.OE4 & The requirement of patient care quality is high. \\
\hline 26.OE5 & The organization provides enough funds to support the adoption of PM-DSS. \\
\hline 27.PU1 & Using PM-DSS can reduce hospital patient care costs. \\
\hline 28.PU2 & Using PM-DSS can improve work efficiency. \\
\hline 29.PU3 & Using PM-DSS can improve patient care quality. \\
\hline 30.PU4 & Using PM-DSS is helpful in assisting the collection and analyze of patient data. \\
\hline 31.PU5 & Using PM-DSS can reduce the amount of time in paper work through PM-DSS. \\
\hline 32.PU6 & Using PM-DSS can improve communication between physicians and hospital staff. \\
\hline 33.PU7 & Using PM-DSS can improve patient safety. \\
\hline 34.PU8 & Overall, PM-DSS is helpful in patient pain management. \\
\hline 35.PE1 & Learning to use PM-DSS would be easy for me. \\
\hline 36.PE2 & It would be easy for me to become skillful at using PM-DSS. \\
\hline 37.PE3 & I would find it easy to get PM-DSS to do what I want it to do. \\
\hline 38.PA1 & I am very satisfied with PM-DSS. \\
\hline 39.PA2 & The PM-DSS functions perform as expected. \\
\hline
\end{tabular}


Table 2 Participant Demographic Data $(\mathrm{N}=101)$

\begin{tabular}{|c|c|c|c|}
\hline Measure & Category & No(\#) & Percent (\%) \\
\hline \multirow[t]{6}{*}{ Age } & $<30$ & 7 & 6.9 \\
\hline & $31-35$ & 50 & 49.5 \\
\hline & $36-40$ & 27 & 26.7 \\
\hline & $41-45$ & 7 & 6.9 \\
\hline & $46-50$ & 9 & 9.0 \\
\hline & $>50$ & 1 & 1.0 \\
\hline \multirow[t]{2}{*}{ Education level } & Bachelor & 91 & 91 \\
\hline & Master & 9 & 9.0 \\
\hline \multirow{4}{*}{$\begin{array}{l}\text { Years of experience in clinical } \\
\text { practice }\end{array}$} & $<2$ & 0 & 0.0 \\
\hline & $2-5$ & 7 & 6.9 \\
\hline & $5-10$ & 34 & 33.6 \\
\hline & $>10$ & 50 & 49.5 \\
\hline \multirow[t]{4}{*}{ Years of experience in using HIS } & $<2$ & 0 & 0.0 \\
\hline & $2-5$ & 2 & 2.0 \\
\hline & $5-10$ & 49 & 48.5 \\
\hline & $>10$ & 50 & 49.5 \\
\hline \multirow[t]{4}{*}{ Experience in using PM-DSS } & 3-6 Months & 60 & 59.4 \\
\hline & 6-9 Months & 20 & 19.8 \\
\hline & $\begin{array}{l}9- \\
\text { 12Months }\end{array}$ & 10 & 10.0 \\
\hline & $>12$ Months & 11 & 10.8 \\
\hline
\end{tabular}

Factors affecting nurse anesthetists' perceived ease of use and perceived usefulness

Consistent with findings obtained by $\mathrm{Lu}$ et al. [39], the results of this study show that perceived information quality has the most significant impact on perceived ease of use. Information quality involves users' evaluations of the integrity, accuracy, format, completeness, and timeliness of a PM-DSS. Prior studies have argued that the quality of information is critical for CDSS development
[68-71]. This can explain the critical role that the information quality of a PM-DSS plays for nurse anesthetists' perceived ease of use of a PM-DSS.

The results show that perceived information quality, computer self-efficacy, and organizational structure all have a significant impact on nurse anesthetists' perceived usefulness of a PM-DSS. The most significant influences on nurse anesthetists' perceived usefulness of a PM-DSS were, in rank order, perceived information quality, computer self-efficacy, and organizational structure. We found perceived information quality to be a significant factor influencing PM-DSS perceived usefulness. Our findings also indicated a consistent result with prior CDSS-related studies [58,71].

Because the perceived information quality generated by a PM-DSS has a considerable influence on clinical decision making, nurse anesthetists need high information quality when providing clinical, medical, and care services for patients. Thus, PM-DSS development should consider the capacities of a PM-DSS to integrate data from different sources; system accuracy, timeliness, and completeness of generated information; and the degree of compliance of information display methods and definition with professional requirements [57]. Thus, hospitals can obtain anticipated benefits of PM-DSS use when the system is well-designed and implemented according to the unique clinician requirements of patient safety. It can help enhance PM-DSS perceptions among medical staff [72].

User self-efficacy refers to the ability that people have in believing that they must apply IT systems to complete specific tasks [46]. Consistent with the results obtained by Ong and Lai [50] and $\mathrm{Wu}$ et al. [2], we found perceived user self-efficacy to be a significant factor affecting PMDSS perceived usefulness. Yi and Hwang [73] found behavior modeling training and observational learning processes to have been linked to increased self-efficacy in the

Table 3 Results of reliability and validity of the research model

\begin{tabular}{|c|c|c|c|c|c|c|c|c|c|c|c|c|c|c|}
\hline & \multirow[b]{2}{*}{ Mean } & \multirow[b]{2}{*}{ SD } & \multicolumn{9}{|c|}{ Correlation matrix } & \multirow{2}{*}{$\begin{array}{l}\text { AVE } \\
(\geq 0.5)\end{array}$} & \multirow{2}{*}{$\begin{array}{l}C R \\
(\geq 0.7)\end{array}$} & \multirow{2}{*}{$\begin{array}{l}\text { Cronbach's } \\
a(\geq 0.7)\end{array}$} \\
\hline & & & SQ & IQ & IN & CS & OS & OE & PU & $\mathrm{PE}$ & PA & & & \\
\hline SQ & 3.643 & 0.688 & 1.000 & & & & & & & & & 0.743 & 0.930 & 0.885 \\
\hline IQ & 3.665 & 0.654 & $0.644^{*}$ & 1.000 & & & & & & & & 0.660 & 0.884 & 0.824 \\
\hline IN & 3.392 & 0.392 & $0.387^{*}$ & $0.296^{*}$ & $1.000^{*}$ & & & & & & & 0.670 & 0.853 & 0.772 \\
\hline CS & 3.677 & 0.619 & $0.372^{*}$ & $0.413^{*}$ & $0.728^{*}$ & 1.000 & & & & & & 0.710 & 0.910 & 0.870 \\
\hline OS & 3.583 & 0.576 & $0.485^{*}$ & $0.519^{*}$ & $0.290^{*}$ & $0.344^{*}$ & 1.000 & & & & & 0.567 & 0.886 & 0.844 \\
\hline OE & 3.573 & 0.488 & $0.330^{*}$ & $0.421^{*}$ & $0.144^{*}$ & $0.315^{*}$ & $0.611^{*}$ & 1.000 & & & & 0.501 & 0.810 & 0.715 \\
\hline PU & 3.733 & 0.594 & $0.728^{*}$ & $0.726^{*}$ & $0.358^{*}$ & $0.540^{*}$ & $0.584^{*}$ & $0.468^{*}$ & 1.000 & & & 0.610 & 0.923 & 0.905 \\
\hline PE & 3.738 & 0.608 & $0.501^{*}$ & $0.572^{*}$ & $0.490^{*}$ & $0.547^{*}$ & $0.439 *$ & $0.364^{*}$ & $0.653^{*}$ & 1.000 & & 0.821 & 0.932 & 0.891 \\
\hline PA & 3.568 & 0.607 & $0.501^{*}$ & $0.620^{*}$ & $0.385^{*}$ & $0.545^{*}$ & $0.530^{*}$ & $0.401^{*}$ & $0.728^{*}$ & $0.725^{*}$ & 1.000 & 0.925 & 0.961 & 0.919 \\
\hline
\end{tabular}

SQ=System Quality; IQ=Information Quality; IN= Innovativeness; CS=Computer Self-Efficacy; OS=Organizational structure; $\mathrm{OE}=$ Organizational environment; $\mathrm{PU}=$ Perceived usefulness; $\mathrm{PE}=$ Perceived ease of use; $\mathrm{PA}=\mathrm{PM}-\mathrm{DSS}$ Acceptance. ${ }^{*} \mathrm{p}<0.001$. 
Table 4 Overall hypothesis validation results

\begin{tabular}{|c|c|c|}
\hline Hypothsis & Path coefficient & Result \\
\hline $\mathrm{H}_{1}$ : IS factors have a significant impact on nurse anesthetists' perceived PM-DSS usefulness. & & Partial support \\
\hline $\mathrm{H}_{1 \mathrm{a}}$ : The system quality of the PM-DSS affects nurse anesthetists' perceived PM-DSS usefulness. & 0.082 & No support \\
\hline$H_{1 b}$ : PM-DSS information quality affects nurse anesthetists' perceived PM-DSS usefulness & $0.451 * * *$ & Support \\
\hline $\mathrm{H}_{2}$ : IS factors have a significant impact on nurse anesthetists' perceived PM-DSS usefulness. & & Partial support \\
\hline $\mathrm{H}_{2 \mathrm{a}}$ : The system quality of the PM-DSS affects nurse anesthetists' perceived PM-DSS ease of use. & 0.099 & No support \\
\hline $\mathrm{H}_{2 \mathrm{~b}}$ : PM-DSS information quality affects nurse anesthetists' perceived PM-DSS ease of use. & $0.267^{*}$ & Support \\
\hline $\mathrm{H}_{3}$ : Human factors significantly affect nurse anesthetists' perceived PM-DSS usefulness. & & Partial support \\
\hline $\mathrm{H}_{3 \mathrm{a}}$ : Computer self-efficacy affects nurse anesthetists' perceived PM-DSS usefulness. & $0.315^{* *}$ & Support \\
\hline $\mathrm{H}_{3 \mathrm{~b}}$ : Personal innovativeness affects nurse anesthetists' perceived PM-DSS usefulness. & 0.102 & No support \\
\hline $\mathrm{H}_{4}$ : Human factors significantly affect nurse anesthetists' perceived PM-DSS ease of use. & & No support \\
\hline $\mathrm{H}_{4 \mathrm{a}}$ : Computer self-efficacy affects nurse anesthetists' perceived PM-DSS ease of use. & 0.191 & No support \\
\hline $\mathrm{H}_{4 \mathrm{~b}}$ : Personal innovativeness affects nurse anesthetists' perceived PM-DSS ease of use. & 0.188 & No support \\
\hline $\mathrm{H}_{5}$ : Organizational factors significantly affect nurse anesthetists' perceived PM-DSS usefulness. & & Partial support \\
\hline $\mathrm{H}_{5 a}$ : Organizational structure affects nurse anesthetists' perceived PM-DSS usefulness. & $0.210^{*}$ & Support \\
\hline$H_{5 b}$ : The organizational affects nurse anesthetists' perceived PM-DSS usefulness. & 0.041 & No support \\
\hline $\mathrm{H}_{6}$ : Organizational factors significantly affect nurse anesthetists' perceived PM-DSS ease of use. & & No support \\
\hline $\mathrm{H}_{6 \mathrm{a}}$ : Organizational structure affects nurse anesthetists' perceived PM-DSS ease of use. & 0.066 & No support \\
\hline $\mathrm{H}_{6 \mathrm{~b}}$ : The organizational affects nurse anesthetists' perceived PM-DSS ease of use. & 0.063 & No support \\
\hline $\mathrm{H}_{7}$ : Nurse anesthetists' perceived PM-DSS ease of use affects system acceptance. & $0.436^{* * *}$ & Support \\
\hline $\mathrm{H}_{8}$ : Nurse anesthetists' perceived PM-DSS usefulness of PMDSS affects system acceptance. & $0.443^{* * *}$ & Support \\
\hline
\end{tabular}
${ }^{*} \mathrm{p}<0.05 .{ }^{* *} \mathrm{p}<0.01 .{ }^{* * *} \mathrm{p}<0.001$.

context of computer training. Quinzio et al. [21] argued that the perceived quality of training strongly influenced user acceptance of an anaesthesia information management system. Huryk [58] found that increased computer experience is the key indicator for positive attitudes. Thus, hospitals should provide adequate technical support and training and incentives to promote and facilitate the PMDSS use of nurse anesthetists, to increase the expected benefits obtained from system use.

Organizational structure is a tool used by enterprises to achieve their objectives and to dominate and coordinate decision-making activities [53]. Consistent with Yusof et al. [42] and Lluch [74], we found that perceived organizational structure is a critical factor affecting nurse anesthetists' perceived PM-DSS usefulness. Nursing staff members are key collectors, generators, and users of patient/client information in healthcare management. Anesthetic practice is a professional specialty that requires communication and coordination between anesthesiologists and nurse anesthetists with varying professional knowledge and skills to increase the quality of care and patient safety during pain management. A PM-DSS is a complex IS that nurse anesthetists use to monitor, record, and store information on analgesia use. When the PMDSS is designed and implemented according to the standardized clinical procedures and processes in pain management, the system can fulfill the information needs of nurse anesthetists and can further improve the perceived usefulness of PM-DSS.

Although several critical factors affecting PM-DSS acceptance by nurse anesthetists have been identified, perceived system quality, personal innovativeness, and organizational environment were found to have no significant effect on perceived ease of use and perceived usefulness of a PM-DSS. System quality includes the characteristics of system response, system reliability, and security. Contrary to the findings of prior studies $[26,39]$, the relationships between perceived system quality and perceived ease of use and perceived usefulness were not significantly supported in this study. A PMDSS is actually a typical CDSS and a subsystem of HIS. As mentioned, CDSS-related studies [68-70] and HISrelated study [75] focused more on perceived information quality than system quality. Consistent with our study, Hsiao et al. [75] found that system quality is not a significant factor for nurses' perceived usefulness and perceived ease of use of HIS. This may account for the insignificance of perceived system quality on perceived ease of use and perceived usefulness of a PM-DSS.

Personal innovativeness represents the degree to which a person is willing to risk testing an innovation [47,48]. A prior study found that perceived personal innovativeness is not a significant factor affecting nursing acceptance of a decision support computer program for cancer 
pain management [13], which is a result that is consistent with those of our study. A possible explanation may be that the mandatory use of a PM-DSS in the case hospital may impede nurse anesthetists' willingness to risk testing the PM-DSS.

An organizational environment is the environment in which an organization exists, including external competition, influence of government policies, characteristics of the target audience, and source of funds required for unit operations $[42,54,55]$. Regarding government policy, nurse anesthetists believe it to be important; thus, no statistically significant difference existed between the nurse anesthetists for this factor. However, if the government requires them to have a PM-DSS, all hospitals agreed that they would begin immediate adoption. Therefore, if the Taiwanese government and state-run insurance agencies implement such a requirement, all hospitals would be forced to comply, irrespective of whether they are ready to do so. In addition, nurses have a firm grasp of their own domains, and they have the authority to delegate MIS tasks to other departments. This separation of duties has contributed to a lack of efficient communication between specialists, and underscores the need for IT facilitators/consultants intimate with both nursing and MIS realities. Considering that IT literacy among nurses is critical and that hospitals may be required by the government to adopt PM-DSSs in the future, nursing specialists who possess a high degree of knowledge and experience with IT/MIS can play a pivotal role as consultants and project facilitators. These are possible reasons for explaining the non-significance of the organizational environment in this study.

\section{Relationships between perceived ease of use, perceived usefulness and PM-DSS acceptance}

The study results show that perceive ease of use and perceived usefulness have a significant impact on PM-DSS acceptance. This implied that, first, PM-DSS acceptance by nurse anesthetists is affected mainly by their perceptions of perceived usefulness, and second, by their perceptions of the perceived ease of use. The findings are consistent with the results of prior studies that investigated the acceptance of systems from the perspectives of health care professionals [25,26,31,32,39,76,77]. Healthcare professionals are more pragmatic, and they should focus more on the usefulness and ease of use of HIT [78]. Nurse anesthetists are likely to accept and use PM-DSSs when they are considered useful and ease to use in their clinical practice related to pain management. A prior TAM study also suggested that perceived usefulness and perceived ease of use of an IT/IS determine the attitudes of people related to IT/IS [29]. Nurse anesthetists are more accepting toward PM-DSS when they have a positive attitude toward it. Thus, perceived usefulness and perceive ease of use are important factors in PM-DSS acceptance from the perspective of nurse anesthetists.

\section{Strengths and limitations of the research}

Pain management is a critical but complex issue in the relief of acute pain, particularly for postoperative and severe pain in cancer patients. The introduction of a pain management-decision support system is critical for nurse anesthetists in assisting pain assessment, diagnosis, and intervention. This investigates factors affecting acceptance of PM-DSS from nurse anesthetists' perspectives. Compared with TAM-based research, our proposed extended TAM model demonstrated a highly totally explained variance better than do traditional TAM (40\%) or TAM2 (59\%) studies [79]. In addition, all respondents were experienced users in HIS and PMDSS. Therefore, the results of this study can be extended to other healthcare professionals with similar levels of experience. The results of this study enable hospital managers to understand the important considerations for nurse anesthetists in accepting PM-DSS, particularly for issues related to enhancing information quality, perceived usefulness, and perceived ease of use of the system. In addition, this study provides useful suggestions for designers and implementers of PM-DSS in further system development.

The findings of this study are subject to three major limitations. First, the study was performed in a single medical center hospital because the development of PM-DSS in Taiwan is in an early stage. In addition, the data derived from questionnaires was provided by participants with more than 3 months of experience using PM-DSS. Respondents answered questions based on their perceptions, experiences, and understandings. Consequently, the data collected may not be adequately objective. Therefore, the respondents may not sufficiently represent the nurse anesthetist' population, inhibiting the generalization of this study. Second, we only tested cross-sectional data collected by nurse anesthetists in one period. Finally, the use of PM-DSS in the case hospital is mandatory. Therefore, the findings of this study should be carefully evaluated when applied to a context of voluntary use.

\section{Conclusions}

This study proposed and validated an extended TAM derived from Davis' original TAM framework and the HOT-fit framework proposed by Yusof et al. to investigate the factors affecting PM-DSS acceptance by nurse anesthetists. The findings showed that nurse anesthetists' PM-DSS acceptance is substantially affected by the perceived usefulness and perceived of use of the system, which is consistent with the results of most TAM studies. In addition, the results showed that perceived information quality is the most significant factor affecting 
perceived ease of use and perceived usefulness. In addition, nurse anesthetists' computer self-efficacy and organizational structure affected PM-DSS acceptance in this study. Through this study, factors influencing nurse anesthetists' PM-DSS acceptance were identified, which can help hospital managers devise appropriate strategies in the early stages of system development when healthcare ISs are introduced.

This study demonstrates the critical role of perceived information quality on the successful implementation of PM-DSS, and the results are consistent with prior CDSS studies [68-71] in that the perceived information quality of a decision support system can influence subsequent decision quality and decision performance. Therefore, the design and implementation of a CDSS, similar to a PM-DSS, should focus on understanding and collecting the informational needs of nurse anesthetists and stakeholders related to PM-DSSs to deliver data with integrity, accuracy, format, completeness, and timeliness for decision making in pain management. Furthermore, hospitals should establish a supportive environment for PM-DSS development and encourage nurse anesthetists and other stakeholders to jointly participate in system design and implementation. Technical support and training should be provided to major users of PM-DSSs to reduce user resistance to PM-DSSs, enhance the computer self-efficacy of nurse anesthetists, and facilitate DSS use. Hospitals should focus on nurse anesthetists' suggestions and feedback during PM-DSS development and implementation to obtain necessary information for system enhancement.

\section{Competing interests}

The author declares that they have no competing interests.

\section{Authors' contributions}

J-LH is the first author of this paper. She took the responsibilities for the conception and design of the study and collection, analysis and interpretation of data. She also helped to compile the submitted paper and made required modifications of the paper. W-CW is the second author of this paper. She is an expert in nurse-anesthetist with over twenty-year experience. She provided assistances in research design, data collection and interpretation. R-FC is the corresponding author of this paper. He helped to propose adequate research concepts and strategies of this study. He also provided useful suggestions in research design and the collection, analysis and interpretation of data. All authors read and approved the final manuscript.

\section{Authors' information}

Ju-Ling Hsiao is an assistant professor of department of Hospital and Health Care Administration at the Chia-Nan University of Pharmacy and Science. Her research interests include nursing informatics, electronic medical record, and hospital information systems. Her published works have appeared in CINComputers, Informatics, Nursing, International Journal of Medical Informatics, Journal of Nursing Research, Telemedicine and e-Health, and Total Quality Management \& Business Excellence.

Wen-Chu Wu completed his MS degree in Hospital and Health Care Administration at the Chia-Nan University of Pharmacy and Science. She is a nurse anesthetist and have worked as nursing administrator in a medical center for the past twenty years. Her research interests include studies of pain management, nursing informatics, and hospital information systems.
Rai-Fu Chen is an assistant professor of department of Information Management at the Chia-Nan University of Pharmacy and Science. His research interests include medical informatics, electronic medical record, and healthcare information systems. His published works have appeared in CINComputers, Informatics, Nursing, International Journal of Medical Informatics, Journal of Nursing Research, Telemedicine and e-Health, and Total Quality Management \& Business Excellence.

\section{Acknowledgements}

Sincere thanks and recognition are given to Chi-Mei Medical Center of Taiwan for funding this study (CMHCR9816).

\section{Author details}

${ }^{1}$ Department of Hospital and Health Care Administration, Chia-Nan University of Pharmacy and Science, Tainan, Taiwan, Republic of China. ${ }^{2}$ Department of Anesthesiology, Chi-Mei Medical Center, Tainan, Taiwan, Republic of China. ${ }^{3}$ Department of Information Management, Chia-Nan University of Pharmacy and Science, No.60, Sec. 1, Erren Rd., Rende Dist, Tainan City 71710, Taiwan, Republic of China.

Received: 6 August 2012 Accepted: 25 January 2013

Published: 29 January 2013

\section{References}

1. Hsaio $J$, Chen RF: An investigation on task-technology fit of mobile nursing information systems for nursing performance. CIN-Comput Inform Nu. 2012, 30(5):265-273.

2. Wu JH, Wang SC, Lin LM: Mobile computing acceptance factors in the healthcare industry: a structural model. Int J Med Inform 2007, 76(1):66-77.

3. Department of Health $(\mathrm{DoH})$ of Taiwan: Nurses Act in Taiwan. Taipei, Taiwan: DoH; 2007.

4. Anderson JA, Willson P: Clinical decision support systems in nursing. CIN-Comput Inform Nu. 2008, 26(3):151-158.

5. Garg AX, Adhikari NK, McDonald H, et al: Effects of computerized clinical decision support systems on practitioner performance and patient outcomes. JAMA 2005, 293(10):1223-1238.

6. Bates DW, Gawande AA: Improving safety with information technology. New Eng J Med 2003, 348(25):2526-2534.

7. de Graaf PMA, van den Eijkel GC, Vullings HJLM, de Mol BAJM: A decisiondriven design of a decision support system in anesthesia. Artif Intell Med 1997, 11:141-153.

8. Miller RA: Computer-assisted diagnostic decision support: history, challenges, and possible paths forward. Adv Health Sci Educ Theory Pract 2009, 14(Suppl 1):89-106.

9. White PF: Patient-controlled an analgesia (part I): historical perspective. In Pain management and anesthesiology. Edited by Ashburn MAP, Fine G, Stnaley TH. Boston: Kluwer; 1998:95-101.

10. Kawamoto K, Houlihan CA, Balas EA, Lobach DF: Improving clinical practice using clinical decision support systems: a systematic review of trials to identify features critical to success. Brit Med J 2005, 330:765-772.

11. Eccles M, McColl E, Steen N, Rousseau N, Grimshaw J, Parkin D, et al: Effect of computerized evidence based guidelines on management of asthma and angina in adults in primary care: cluster randomised controlled trial. Brit Med J 2002, 325:941.

12. Eccles M, Hawthorne G, Whitty P, Steen N, Vanoli A, Grimshaw J, et al: A randomised controlled trial of a patient based diabetes recall and management system: the DREAM trial: a study protocol. BMC Health Serv Res 2002, 2:5.

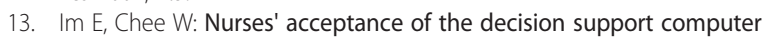
program for cancer pain management. CIN-Comput Inform Nu 2006, 24(2):95-104.

14. Lattimer V, George S, Thompson F, Thomas E, Mullee M, Turnbull J, et al: Safety and effectiveness of nurse telephone consultation in out of hours primary care: randomized controlled trial. Brit Med J 1998, 317:1054-1059.

15. Salisbury C, Chalder M, Scott TM, Pope C, Moore L: What is the role of walk-in centres in the NHS? Brit Med J 2002, 324:399-402.

16. Berry PH, Dahl JL: The new JCAHO pain standards: implications for pain management nurses. Pain Manag Nurs 2000, 1(1):3-12.

17. Macintyre PE: Safety and efficacy of patient-controlled analgesia. Brit J Anaesth 2001, 87(1):36-46.

18. Ripamonti C: Pain management. Annals of Oncol 2012, 23(s10):x294-x301. 
19. Sun V, Borneman T, Piper B, Koczywas M, Ferrell B: Barriers to pain assessment and management in cancer survivorship. J Cancer Surviv 2008, 2:65-71.

20. Randell R, Mitchell N, Dowding D, Cullum N, Thompson C: Effects of computerized decision support systems on nursing performance and patient outcomes: a systematic review. Health Serv Res Policy 2007, 12(4):242-251.

21. Quinzio L, Junger A, Gottwald B, Benson M, Hartmann B, Jost A: User acceptance of an anaesthesia information management system. Eur J Anaesth 2003, 20(12):967-972.

22. Im $E$, Chee $W$ : Decision support computer program for cancer pain management. CIN-Comput Inform Nu 2003, 21(1):12-21.

23. Dillon TW, McDowell D, Salimian F, Conklin D: Perceived ease of use and usefulness of bedside-computer systems. CIN-Comput Inform Nu 1998, 16(3):151-156

24. Van Schaik P, Bettany-Saltikov JA, Warren JG: Clinical acceptance of a lowcost portable system for postural assessment. Behav Inform Technol 2002, 21(1):47-57.

25. Aldosari B: User acceptance of a picture archiving and communication system (PACS) in a Saudi Arabian hospital radiology department. BMC Med Inform Decis 2012, 12:44. doi:10.1186/1472-6947-12-44.

26. Chen RF, Hsaio JL: An investigation on physicians' acceptance of hospital information systems: a case study. Int J Med Inform 2012. doi:10.1016/j. ijmedinf.2012.05.003. in press.

27. Randell R, Dowding D: Organisational influences on nurses' use of clinical decision support systems. Int J Med Inform 2010, 79(6):412-421.

28. Yarbrough AK, Smith TB: Technology acceptance among physicians: a new take on TAM. Med Care Res Rev 2007, 64(6):650-672.

29. Davis FD: Perceived usefulness, perceived ease of use, and user acceptance of information technology. Mis Quart 1989, 13(3):319-340.

30. Lee $Y$, Kozar KA, Larsen KRT: The technology acceptance model: past, present, and future. Commun A/S 2003, 12(50):752-780.

31. Chau PYK, Hu PJ: Information technology acceptance by professionals: a model comparison approach. Decision Sci 2001, 23(4):699-719.

32. Chau PYK, Hu PJ: Examining a model of information technology acceptance by individual professionals: an exploratory study. J Manage Inform Syst 2002, 18(4):191-229.

33. Dixon DR, Stewart M: Exploring information technology adoption by family physicians: survey instrument validation. In Proceedings of the American medical informatics association 2000 on session 569-current issues in medical informatics edition; November 4-8 2000. Edited by American Medical Informatics Association. Los Angeles, CA:; 2000:185-189.

34. Gagnon MP, Godin G, Gagne C, Fortin JP, Lamothe L, Reinharz D, Cloutier A: An adaptation of the theory of interpersonal behavior to the study of telemedicine adoption by physicians. Int J Med Inform 2003, 71(2/3):103-115.

35. Hu PJ, Chau PYK, Sheng ORL, Tam KY: Examining the technology acceptance model using physician acceptance of telemedicine technology. J Manage Inform Syst 1999, 16(2):91-112.

36. Kidd MR, McPhee W: The lost generation: IT education for healthcare professionals. Med J Australia 1999, 171(10):510-511.

37. Scott RE: e-records in health-preserving our future. Int J Med Inform 2007 , 76:427-431.

38. Zhang HY, Cocosila M, Archer N: Factors of adoption of mobile information technology by homecare nurses: a technology acceptance model 2 approach. CIN-Comput Inform Nu 2010, 28(1):49-56.

39. Lu CH, Hsiao JL, Chen RF: Factor determining nursing acceptance of hospital information systems. CIN-Comput Inform Nu 2012, 30(5):257-264.

40. Wu IL, Li JY, Fu CY: The adoption of mobile healthcare by hospital's professionals: an integrative perspective. Decis Support Syst 2011, 51(3):587-596.

41. Fitterer R, Mettler T, Rohner P, Winter R: Taxonomy for multi-perspective assessment of the value of health information systems. Int $J$ of Healthcare Technology and Management 2011, 12(1):45-61.

42. Yusof MM, Kuljis J, Papazafeiropoulou A, Stergioulas LS: An evaluation framework for health information systems: human, organization and technology-fit factors (HOT-fit). Int J Med Inform 2008, 77(6):386-398.

43. Oroviogoicoechea C, Elliott B, Watson R: Review: evaluating information systems in nursing. J Clin Nurs 2008, 17(5):567-575.

44. DeLone WH, McLean ER: The DeLone and McLean model of information systems success: a ten-year update. J Manage Inform Syst 2003, 19(4):9-30.

45. Compeau DR, Higgins CA: Computer self-efficacy: development of a measure and initial test. Mis Quart 1995, 19(2):189-211.
46. Venkatesh V, Morris M, Davis G, Davis F: Use acceptance of information technology: toward a unified view. MIS Quart 2003, 27(3):425-478.

47. Flynn LR, Goldsmith RE: A validation of the goldsmith and hofacker innovativeness scale. Educ Psychol Meas 1993, 53(4):1105-1116.

48. Midgley DF, Dowling GR: Innovativeness: the concept and its measurement. J Consum Res 1978, 4(4):229-242.

49. Vijayasarathy LR: Predicting consumer intentions to use online shopping: the case for an augmented technology acceptance model. Inform Manage 2004, 41(6):747-762.

50. Ong CS, Lai JY: Gender differences in perceptions and relationships among dominants of e-learning acceptance. Comput Hum Behav 2006, 22(5):816-829.

51. Agarwal R, Karahanna E: Time flies when you're having fun cognitive absorption and beliefs about information technology usage. Mis Quart 2000, 24(4):665-694.

52. Karahanna E, Ahuja M, Srite M, Galvin J: Individual differences and relative advantage: the case of GSS. Decis Support Syst 2002, 32(4):327-341.

53. Sciulli LM: How organizational structure influences success in various types of innovation. J Retail Bank Serv 1998, 20(1):13-18.

54. Ammenwerth $\mathrm{E}$, de Keizer $\mathrm{N}$ : An inventory of evaluation studies of information technology in health care trends in evaluation research 1982-2002. Methods Inf Med 2005, 44:44-56.

55. Kaplan B: Evaluating informatics applications-some alternative approaches: theory, social interactionism, and call for methodological pluralism. Int J Med Inform 2001, 64(1):39-56.

56. Kaplan B: Organizational evaluation of medical information resources. In Evaluation methods in medical informatics. Edited by Friedman CP, Wyatt JC. New York: Springer; 1997:255-280.

57. Wakefield DS, Halbesleben JRB, Ward MM, Qiu Q, Brokel J, Crandall D: Development of a measure of clinical information systems expectations and experiences. Med Care 2007, 45(9):884-890.

58. Huryk $L A$ : Factors influencing nurses attitudes towards healthcare information technology. J Nurs Manage 2010, 18(5):606-612.

59. Schectman JM, Schorling JB, Nadkarni MM, Voss JD: Determinants of physician use of an ambulatory prescription expert system. Int J Med Inform 2005, 74(9):711-717.

60. Wixom BH, Todd PA: A theoretical integration of user satisfaction and technology acceptance. Inform Syst Res 2005, 16(1):85-102.

61. Hilton A, Skrutkowski M: Translating instruments into other languages: development and testing processes. Cancer Nurs 2002, 25(1):1-7.

62. Otieno OG, Toyama H, Asonuma M, Kanai-Pak M, Naitoh K: Nurses' Views on the use, quality and user satisfaction with electronic medical records: questionnaire development. J Nurs Adm 2007, 60(2):209-219.

63. Fornell C, Larcker DF: Evaluating structural equation models with unobservable variables and measurement error. J Mark Res 1981, 18(1):39-50.

64. Nunnally J: Psychometric theory. New York: McGraw-Hill; 1978.

65. Hair JF, Anderson RE, Tatham RL, Black WC: Multivariate data analysis. 6th edition. New Jersey: Prentice Hall; 1998.

66. Wold H: Partial least squares. In Encyclopedia of statistical sciences. Volume 6. Edited by Kotz S, Johnson NL. New York: Wiley; 1985:581-591.

67. O'Leary-Kelly SW, Vokurka RJ: The empirical assessment of construct validity. J Oper Manag 1998, 16(4):387-405.

68. Aronsky D, Haug PJ: Assessing the quality of clinical data in a computerbased record for calculating the pneumonia severity index. J Am Med Inform Assoc 2000, 7(1):55-65.

69. Berner ES, Kasiraman RK, Yu F, Ray MN, Houston TK: Data quality in the outpatient setting: impact on clinical decision support systems. In Proceedings of the American medical informatics association 2005; November 30-December 1 2005. Edited by American Medical Informatics Association. Austin: 2005:41-45

70. Hogan WR, Wagner MM: Accuracy of data in computer-based patient records. J Am Med Inform Assoc 1997, 4(5):342-355.

71. Hsieh TC, Kuperman GJ, Jaggi T, et al: Characteristics and consequences of drug-allergy alert overrides in a computerized physician order entry system. J Am Med Inform Assoc 2004, 11(6):482-491.

72. Marin HF: Nursing informatics: advances and trends to improve health care quality. Int J Med Inform 2007, 76(supl 2):S267-S269.

73. Yi MY, Hwang Y: Predicting the use of web-based information systems: self-efficacy, enjoyment, learning goal orientation, and the technology acceptance model. Int J Hum-Comput St 2003, 59(4):431-449. 
74. Lluch M: Healthcare professionals' organisational barriers to health information technologies - a literature review. Int. J. Med. Inform. 2011 , 80(12):849-862.

75. Hsiao JL, Chang HC, Chen RF: A study of factors affecting acceptance of hospital information systems: a nursing perspective. J Nurs Res 2011, 19(2):150-160.

76. Aggelidis VP, Chatzoglou PD: Using a modified technology acceptance model in hospitals. Int. J. Med. Inform 2009, 78(2):115-126.

77. Yu P, Li H, Gagnon MP: Health IT acceptance factors in long-term care facilities: a cross-sectional survey. Int. J. Med. Inform 2009, 78(4):219-229.

78. Pare G, Sicotte $\mathrm{C}$, Jacques H: The effects of creating psychological ownership on physicians' acceptance of clinical information systems. J. Am. Med. Inform. Assoc 2006, 13(2):195-205.

79. Chismar WG, Wiley-Patton S: Does the extended technology acceptance model apply to physicians. In Proceednas of the 36th Hawaii international conference on system sciences 2003. Edited by IEEE Computer Society. 2005.

doi:10.1186/1472-6947-13-16

Cite this article as: Hsiao et al.: Factors of accepting pain management decision support systems by nurse anesthetists. BMC Medical Informatics and Decision Making 2013 13:16.

\section{Submit your next manuscript to BioMed Central and take full advantage of:}

- Convenient online submission

- Thorough peer review

- No space constraints or color figure charges

- Immediate publication on acceptance

- Inclusion in PubMed, CAS, Scopus and Google Scholar

- Research which is freely available for redistribution 